\title{
Modern Approach of Manufacturing Methods - A Review
}

\author{
C.Hemadri Chadalavada, G.Akash, K.Thiyagaraj, V.Manojkumar, R.Karthikeyan \\ Dept.of Mechanical Engineering, R.M.K.College of Engineering and Technology, Thiruvallur, Tamilnadu \\ chd311@gmail.com
}

\begin{abstract}
Engineering applications find its use of structural materials like copper, titanium, aluminium and composites with extensive properties such as high resistance to corrosion, light in weight, etc. Binding of dissimilar metals as composite structure is of major attraction towards aerospace and automotive applications, because of its wide technological benefits. In recent days lot of changes have been developed in manufacturing of structures. Friction stir welding with weaving methods, abrasive jet machining with changes in nozzle design and severe plastic deformation of welded joints have been done to join various dissimilar materials and machining of composites.

Keywords: Stir welding; Bonding; Severe plastic deformation; Abrasive; Machining

1. Introduction

Friction stir welding is a newly developed process which is environmentally friendly. This process enables better stirring action in the weld bead which enhances the joint strength. A study to understand the influence of tool geometry on mechanical, micro structural properties and defect formation in FSW of an aluminum alloy was done. Defect free, high tensile strength of weld joints were reported for a shoulder diameter of $20 \mathrm{~mm}$ and a pin diameter of $6 \mathrm{~mm}$. Al-Cu plates were successfully friction stir welded by keeping the tool to the aluminum side i.e., away from the weld line. Welded joint exhibited a superior metallurgical bonding on the $\mathrm{Al}-\mathrm{Cu}$ interface which was responsible for the formation of a thin, continuous and uniform Intermetallic Compound (IMC) layer. Welded joints failed in the HAZ of the aluminum side during tensile test. The results exposed that the process has appreciably enhanced the microstructure of the A413 Al alloy by avoiding welding defects such as porosity and $\mathrm{Si}$ segregation (1-3)

The average grain size reduced in the nugget zone was reported after the addition of nano particles. The formations of IMCs on fracture surface were responsible for the lower weld strength. Proper stirring of base metals was achieved through tool pin offset. This led to the better mechanical properties and surface characteristics of the weldments in $\mathrm{Al} / \mathrm{Cu}$ joints. The investigation confirmed that successful $\mathrm{Al} / \mathrm{Cu}$ joints cannot be obtained without tool pin offset. The reinforced graphene nano/micro particles were compacted initially along the FSW direction in elliptical shape groove to prevent spillage of particles during FSW $(3,4)$

Abrasive jet machining is a unconventional or

suitable for making micro holes in brittle and composite materials involved in the machining of many industrial components. Fiber reinforced polymer composite materials find extensive use in aircraft, automobile industries, and house hold applications due to its lightweight, excellent strength, corrosion resistance and attractive fracture toughness. These composites, when machined, suffer heavy delamination when conventional machining process like drilling is used. The machining time using the conventional nozzle in machining of the above composites is also found to be high.(5-8)

To understand the machining characteristics of above composites, in this research work, holes were made on two different fiber reinforced polymer composites, namely, carbon fibre reinforced polymer composite (CFRP) and glass fiber reinforced polymer composite (GFRP) using abrasive jet machining. The existing conventional nozzle was modified by incorporating internal threads inside the nozzle.These internal threads induce swirling motion to the flow of abrasive particles, thereby increasing the material removal rate which, in turn, reduces machining time. This was evident from the computational fluid dynamics analysis performed for understanding the flow of the abrasive particle inside the nozzle. Even though few methods have been suggested by the researchers for imparting swirling motion to the abrasive particles, these methods require considerable modification in the existing equipment which is highly expensive. This novel method of incorporating internal threads is unique and proves to be very simple and efficient compared to the other methods available. Also, available literature shows the scanty nature of any detailed study on abrasive jet machining of carbon fibre and glass fibre composites(9-15)
\end{abstract} modern machining process, which is eminently 
Equal Channel Angular Pressing produces ultrafine grained structured materials which is most advantageous in comparison with most Severe Plastic Deformation processes.. The channel angle is the most dominant process parameter, depending on which the property of the processed material varies significantly. Hence to exploit the advantage of this process and to fabricate materials with tailor made properties, it is desirable to have access to a wide range of channel angles $(16,17)$

\section{Friction stir Welding}

The investigation is limited to create an extensive and comprehensive mechanism to obtain defect free FSW joints. The investigation is limited to maximum process parameters via, spindle speed $1500 \mathrm{RPM}$, transverse speed $90 \mathrm{~mm} / \mathrm{min}$ and axial load of $20 \mathrm{kN}$. This study brings out the influence of tool pin offset, weaving tool motion and graphene nano particle reinforcement on $\mathrm{Al}-\mathrm{Cu}$ joints.(1820). This study also provides a comparison of the above joint properties with and without the addition of grapheme nano particle reinforcement. The material flowability and tool Tribology are also discussed for the above conditions.

The objective of this study is described as follows:

- To Study the effect of pin-offset on improvement in Mechanical properties and micro structural properties of dissimilar $\mathrm{Al}$ and $\mathrm{Cu}$ joints made using FSW.

- Understand the novel geometric tool path movement in the weld zone and to study its effects on mechanical properties and micro structural characterization through efficient stirring action over the dispersion of metallic phases.

Experimental work was carried out in 3-axis Vertical milling center with the FSW tool attached to the collet of the spindle. The next is the eccentric motion of the tool with and without pin offset. The welds were processed using the process parameters such as welding speed, tool pin plunge depth, and rotational speed of the tool.

\subsection{Effect of Pin offset}

Linear weld with Pin offset produces enhanced mechanical properties viz; Tensile strength 190 $\mathrm{MPa}$, yield strength $160 \mathrm{MPa}$, notch tensile strength of $140 \mathrm{MPa}$, elongation of $8 \%$ and impact strength of 9.4 Joules. Tensile Strength value is $3 \%$ higher when compared to the weld made without tool pin offset. Eccentric weave FSW with pin offset have possessed enhanced mechanical properties viz; Tensile strength $217 \mathrm{MPa}$, yield strength $182 \mathrm{MPa}$, notch tensile strength of 152 $\mathrm{MPa}$, elongation of $10 \%$ and impact strength of 12.4 Joules. This value is around $20 \%$ higher than the Weave FSW made without pin offset. Hardness value at weld zone is $97 \mathrm{HV}$ for the weld made, whereas hardness value of $105 \mathrm{HV}$ was observed in the weld zone for weld made using the tool without pin offset.(21)

\subsection{Effect of Weave Bead Weld}

Friction stir weave weld gives effective mixing of phase material. The dwell period of the tool travel of the weave tool pattern is twice the period of the linear weld. The tensile strength of the weave welds with dissimilar joints possesses the higher weld strength, when compared to their base metal's strength. This is because of the proper stirring of the copper particles, which is harder to be mixed. The formation of the intermetallic components increases the influence of the joint strength. The welds with the eccentric profile and pin offset configuration possess a tensile strength value of $217 \mathrm{MPa}$. This is because of the proper stirring of the base metals with the displacement of grain particles having different melting points and thermal conductivities. The yield strength value is found to be $187 \mathrm{MPa}$. The percentage of elongation is found to be $10 \%$.

Under the weave-welding pattern without tool offset the flow of material could increase the stirring time of materials thus increasing the plasticine area of the welding zones. This increases the visco plastic state of the metal at the weld zone, which again leads to the formation of surface serrations due to the turbulence effect of the tool. Under weave welding with tool offset conditions, the stir zone along the tool path movement achieves an intensive plastic deformation and frictional heat, resulting in the formation of crystallized finegrained microstructure. This could avoid the fragmental cracks and increase the tensile strength with the offset of tool pin.

\subsection{Abrasive Jet Machining}

On the basis of literature survey, predominant abrasive jet process parameters were selected and used for the investigation. Machining time, material removal rate, kerf characteristics (top kerf \& bottom kerf), kerf angle and surface roughness (Ra) were investigated. Artificial neural network was applied to optimize the process parameters for a higher material removal rate, low kerf angle, low surface roughness and high quality machined surface (22-25)

This research work is divided into two phases. In the first phase, abrasive jet machining was carried out in carbon fibre reinforced polymer composites using threaded and unthreaded nozzles. The outcome of this work was further evaluated by measuring the machining time, material removal rate, kerf angle and surface roughness. In the 
second phase, the experimental work was extended further to machine glass fiber reinforced polymer composites using threaded and unthreaded nozzles. Macro graph was captured using an optical microscope to understand the delamination and the quality of the machined surfaces. Top kerf and bottom kerf were also measured using the optical microscope. Further Mitutoyo SJ210 equipment was used for measuring the surface roughness of the machined holes.Artificial neural network models were developed for predicting the optimized process parameters in the machining of both carbon fibre and glass fibre reinforced polymer composites using threaded and unthreaded nozzle. The experimental and ANN predicted results have a very close correlation with 0.9 coefficients of determination.

The abrasive jet machining process with a novel internal threaded nozzle increased the material removal rate, thereby reducing drastically the machining time in both carbon fibre and glass fibre reinforced polymer composites. Considering the fact that very limited studies have been done on carbon fibre reinforced polymer composites and glass fibre reinforced polymer composites, a newly designed nozzle has made further improvement to the quality of machining by decreasing the surface roughness of the machined surface.(26-33)

\section{Welding of Non-Ferrous materials}

Titanium is one of the most important non-ferrous metals, which finds extensive application in the aerospace industry, because of its lightweight, excellent corrosion resistance, high strength level, attractive fracture behaviour and high melting point $\left(1678^{\circ} \mathrm{C}\right)$. Welding of titanium alloys is difficult because titanium is extremely reactive at high temperatures. During welding, titanium alloys pick up oxygen and nitrogen from the atmosphere easily. It has become necessary to develop unique welding procedures and techniques to control the alpha/beta phase transformations and precipitation reactions responsible for the deleterious weld properties in these materials. Current pulsing has been used by several investigators to obtain grain refinement in weld fusion zones and improvement in weld mechanical properties. The main objective of the present investigation is to evaluate the tensile, impact, hardness, fusion zone grain size and corrosion behaviour of Pulsed Current Gas Tungsten Arc Welded (PCGTAW) Ti-6Al-4V titanium alloy weldments.(18,34-38)

The rolled sheets of Ti-6Al-4V titanium alloy were cut into the required sizes (100 x 150 x $1.6 \mathrm{~mm}$ ). Square butt joint configuration was prepared to fabricate autogenous pulsed current GTAW joints. Due to wide range of factors, it has been decided to use four factors, five levels, central composite design matrix to optimise the experimental conditions. The fabricated joints have been machined to the required size and dimensions using wire cut EDM process to prepare tensile, impact, hardness, corrosion and microstructural analysis. All the specimens have been prepared as per the ASTM specifications. Tensile properties such as yield strength, tensile strength, notch tensile strength, percentage of elongation and notch strength ratio have been evaluated by conducting the test in Universal Testing Machine. Sub size specimens have been prepared to evaluate impact toughness and pendulum type impact testing machine has been used to evaluate the impact toughness. Potentiostat (Gill AC) has been used to determine the corrosion rate. Metallographic procedures have been followed to prepare the specimens for corrosion, micro-hardness and microstructural analysis. (19,39-47)

Mathematical models representing all the responses have been developed and the adequacy of the model was checked by ANOVA. The models have been validated by determining the coefficient of determination $\left(\mathrm{r}^{2}\right)$. In this investigation an attempt has been made to optimise pulsed current GTA welding parameters to attain maximum grain refinement in the Ti-6Al-4V Titanium alloy. The traditional Hooke and Jeeve's method is used as an optimisation tool to search the optimum values of the process variables. Contour plots and response plots were drawn to study the behaviour of the models. By generating contour plots using software for response surface analysis, the optimum is located with reasonable accuracy by characterising the shape of the surfaces.

Diffusion bonding is a solid-state joining process capable of joining a wide range of metal and ceramic combinations to produce both small and large components. The process is dependent on a number of parameters, in particular, time, applied pressure, bonding temperature and method of heat application. Other examples of solid-state joining include cold pressure welding, friction welding, magnetically impelled arc butt (MIAB) welding and explosive welding.

\section{Conclusions}

The characteristics of weldment through the novel eccentric weave tool path movement, severe plastic deformation and machining of composites by abrasive jet machining were investigated and, the following conclusions can be drawn. 
1. From the observations of flowability characteristics, the surface serrations and accumulated layer structures in various locations of the weldments correlated with the eccentric motion of the tool. This confirms the novel method of tool pin offset with eccentric stir pattern enhancing the properties of the weldments.

2. The eccentric motion with tool pin offset makes a smooth material flow and higher pulsating effect in the interface led to the highest tensile and impact strength, but the normal tool profile produces the lowest tensile and impact strength.

3. Severe plastic deformation can be used to cold work welded specimen thereby increasing the joint strength and eliminating the possibility of post weld heat treatment

4. Machining of composites by using a recently developed nozzle increases the efficiency of the process and creates less defect free surfaces.

\section{References}

1.Balasubramanian M, Jayabalakrishnan D. Influence of Pin Offset and Weave Pattern on the Performance of Al-Cu Joints Reinforced with Graphene Particles. International Journal of Automotive and Mechanical Engineering. 2020;17(3):8186-96.

2.Jayabalakrishnan, D. \& Balasubramanian, M. An Over Review of The Effect of Process Parameters, Tool Geometry And Joint Geometry In Friction Stir Welding And Friction Stir Processing. International Journal of Applied Engineering Research. 2019, 10. 448-455.

3.Balasubramanian M, Murali S, Jayabalakrishnan D. Friction stir welding with weaving arrangement. In: Materials Today: Proceedings. 2021. p. 3596-600

4.Balasubramanian M, Jayabalakrishnan D. Influence of Pin Offset and Weave Pattern on the Performance of Al-Cu Joints Reinforced with Graphene Particles. International Journal of Automotive and Mechanical Engineering. 2020;17(3):8186-96.

5.Balasubramanian M., Jayabalakrishnan D., Hemadri C., Ashwin B. (2021) Application of Back Propagation Algorithm in Optimization of Weave Friction Stir Welding - A Study. In: Palanikumar K., Natarajan E., Sengottuvelu R., Davim J.P. (eds) Futuristic Trends in Intelligent Manufacturing. Materials Forming, Machining and Tribology.
Springer, Cham. https://doi.org/10.1007/978-3-03070009-6_7

6.Balasubramanian M, Loganathan TG, Srimath R. An overview: characterization of natural fiber reinforced hybrid composites. World Journal of Engineering. Emerald Group Holdings Ltd.; 2021. https://doi.org/10.1108/WJE-07-2021-0409

7.Balasubramanian M, Madhu S. Performance evaluation of newly designed nozzle on abrasive jet machining characteristics of laminated composites. World Journal of Engineering. 2021; http://dx.doi.org/10.1108/WJE-10-2020-0513

8.Elango A, Kumar KV, Loganathan TG, Priya RK, Shobana S, Balasubramanian $M$, et al. Characterization of alkali treated Nelumbo nucifera fiber and properties of its reinforced composite. Journal of Natural Fibers. 2021; https://doi.org/10.1080/15440478.2020.1870640

9.Madhu S, Balasubramanian M. Challenges in abrasive jet machining of fiber-reinforced polymeric composites - a review. Vol. 18, World Journal of Engineering. Emerald Group Holdings Ltd.; 2021. p. 251-68.

10.Balasubramanian M, Madhu S. Effect of the threaded nozzle on delamination and surface texture of PEEK CF30 composite machined by abrasive jet. World Journal of Engineering. 2021; https://doi.org/10.1108/WJE-03-2021-0186

11.Balasubramanian M, Madhu S, Murali S. Augmenting the design of a nozzle used in abrasive jet machining process with computational fluid dynamics. In: Materials Today: Proceedings. Elsevier Ltd; 2021. p. 3521-5.

12.Balasubramanian M, Madhu S, Neural Network based Optimization of Abrasive Jet Process Parameters in Machining GFRP Composites, International Journal of Engineering Technology, Management and Applied Sciences, 2017, 5(5), pp.425-435.

13.Thozhur Loganathan, K. Vinoth Kumar, K. Ayyappa, G. Mahendran \& G. Venkatachalam(2020)Mechanical and Vibrational Property Evaluation of Banana Fiber Epoxy Sandwich Composite with Steel Wire Mesh Core,Journal of Natural Fibers,DOI: 10.1080/15440478.2020.1848744

14.Balasubramanian M, Madhu S, "A review on Abrasive Jet Machining Process Parameters", Journal of Applied Mechanics and Materials. 766-767, 2015, pp.629-634. 
15.Balasubramanian M, Madhu, Surface Roughness Assessment Based on Digital Image Texture Analysis of CFRP Composites Machined by Swirling Abrasives, Journal of Engineering Science and Technology, 15(5), 2020.

16. Balasubramanian M, Sadasivan N, Murali S. Influence of processing route on bonding of AA6082 and MgAZ31B by severe plastic deformation process. In: Materials Today: Proceedings. Elsevier Ltd; 2021. p. 3716-22.

17.Sadasivan N, Balasubramanian M, Rameshbapu BR. A comprehensive review on equal channel angular pressing of bulk metal and sheet metal process methodology and its varied applications. Vol. 59, Journal of Manufacturing Processes. Elsevier Ltd; 2020. p. 698-726.

18.Balasubramanian M,Jayabalakrishnan D, Prabhu $\mathrm{P}$, Tamilselvam $\mathrm{M}$, An overview of the effect of process parameters, tool geometry and joint geometry in friction stir welding and friction stir processing, International journal of applied engineering research, 2015, 10(71), pp.448-455

19.Elangovan K, Balasubramanian V, Babu S, Balasubramanian M. Optimising Friction Stir Welding parameters to maximise tensile strength of AA6061 aluminium alloy joints. International Journal of Manufacturing Research. 2008;3(3):32134.

20.Babu S, Elangovan K, Balasubramanian V, Balasubramanian M. Optimizing friction stir welding parameters to maximize tensile strength of AA2219 aluminum alloy joints. Metals and Materials International. 2009;15(2):321-30.

21.Balasubramanian M, Jayabalakrishnan D, A Study on Friction Stir Welding on various MaterialsA Review, International Journal of Engineering Technology Science and Research, 2017, 4(5), pp. 247-253.

22.Madhu S, Balasubramanian M. Influence of Seaweed Filler on Dry Sliding Wear of Carbon Fiber Reinforced Epoxy Composites. Journal of Natural Fibers. 2020;1-11.

23.Madhu S, Balasubramanian $\mathrm{M}$. Challenges in abrasive jet machining of fiber-reinforced polymeric composites - a review. Vol. 18, World Journal of Engineering. Emerald Group Holdings Ltd.; 2021. p. 251-68.

24.Balasubramanian V, Senthilkumar J, Balasubramanian M. Optimization of the corrosion behavior of $\mathrm{AA} 7075 \mathrm{Al} / \mathrm{SiCP}$ and $\mathrm{Al} / \mathrm{Al} 2 \mathrm{O} 3$ composites fabricated by powder metallurgy. Journal of Reinforced Plastics and Composites. 2008;27(15):1603-13.

25.Madhu S, Balasubramanian M. Influence of nozzle design and process parameters on surface roughness of CFRP machined by abrasive jet. Materials and Manufacturing Processes. 2017;32(9):1011-8.

26.Madhu S, Balasubramanian M. Effect of abrasive jet process parameters on machining glass fibre reinforced polymer composite: Einfluss der abrasivenStrahl-

ProzessparameterzurBearbeitungglasfaserverstärkter Polymer-Verbundwerkstoffe. Materialwissenschaft und Werkstofftechnik. 2017;48(11):1146-57.

27.Madhu S, Balasubramanian M. Effect of swirling abrasives induced by a novel threaded nozzle in machining of CFRP composites. International Journal of Advanced Manufacturing Technology. 2018;95(9-12):4175-89.

28. Balasubramanian M, Madhu S. Evaluation of delamination damage in carbon epoxy composites under swirling abrasives made by modified internal threaded nozzle. Journal of Composite Materials. 2019;53(6):819-33.

29.Madhu S, Balasubramanian M. Impact of Nozzle Design on Surface Roughness of Abrasive Jet Machined Glass Fibre Reinforced Polymer Composites. Silicon. 2018;10(6):2453-62.

30.Choudary MV, Nagaraja A, Sai KOC, Balasubramanian M. Characterization of laminate sandwiched with stainless steel and glass fibre. In: Materials Today: Proceedings. 2020. p. 847-52.

31.Vinoth Kumar K, Loganathan, T.G. and Madhu, S., 2020. Wear characteristics of GFRP composites on exposure to rough surface. Materials Today: Proceedings, 22, pp.1085-1091.

32.Vinoth Kumar, K.,Pavendhan, R., Subramaniyan, G.G.R. and Loganathan, T.G., 2020. Effect of bio waste (conch shell) particle dispersion on the performance of GFRP composite. Journal of Materials Research and Technology, 9(4), pp.71237135 .

33.Madhu S, Balasubramanian M. Effect of swirling abrasives induced by a novel threaded nozzle in machining of CFRP composites. 2018; https://link.springer.com/article/10.1007\%2Fs00170017-1488-2

34.Balasubramanian, M. \& V., Jayabalan\& Balasubramanian, V.. (2008). Developing 
mathematical models to predict grain size and hardness of argon tungsten pulse current arc welded titanium alloy. Journal of Materials Processing Technology - J MATER PROCESS TECHNOL. 196. 222-229. 10.1016/j.jmatprotec.2007.05.039.

35.Balasubramanian Professor M, Kumar R. Prediction of Reliability in Friction Welded Dissimilar Joints By Weibull Distribution. 2015. http://dx.doi.org/10.1115/IMECE2015-50621

36.Balasubramanian M, Murali S, Hemadri C, Kumar R. A new method of dissimilar friction welding of titanium to stainless steel. In: Materials Today: Proceedings. Elsevier Ltd; 2021. p. 3644-7.

37.Senthilkumar J, M B, Balasubramanian M, Loganathan TG. Effect of FW conditions on mechanical and microstructural characteristic of AA6061/SiC/Graphite hybrid composites joint by empirical relationship. Surface Topography: Metrology and Properties 2021 Dec 1;9(4):045042. Available from: https://iopscience.iop.org/article/10.1088/2051$672 \mathrm{X} / \mathrm{ac} 4148$

38.M.Balasubramanian, R.Kumar and S.Gopinath, Multi-objective optimisation of friction welding parameters in joining titanium alloy and stainless steel with a novel interlayer geometry, Advances in Materials Processing and Technologies, 1(6) 2020, pp.25-39

39.Balasubramanian M, Murali S, Hemadri C, Kumar R. A new method of dissimilar friction welding of titanium to stainless steel. In: Materials Today: Proceedings. Elsevier Ltd; 2021. p. 3644-7.

40.Balasubramanian M, Sadasivan N, Murali S. Influence of processing route on bonding of AA6082 and MgAZ31B by severe plastic deformation process. In: Materials Today: Proceedings. Elsevier Ltd; 2021. p. 3716-22.

41.Balasubramanian, M. \& V., Jayabalan\& Balasubramanian, V.. (2008). Developing mathematical models to predict grain size and hardness of argon tungsten pulse current arc welded titanium alloy. Journal of Materials Processing Technology - J MATER PROCESS TECHNOL. 196. 222-229. 10.1016/j.jmatprotec.2007.05.039.

42.Balasubramanian M, Choudary MV, Nagaraja A, Sai KOC. Cold metal transfer process - A review. In: Materials Today: Proceedings. Elsevier Ltd; 2020. p. 543-9.

43.Senthilkumar J, Suresh P, Kumar M, Balasubramanian \& M. Effect of Post Weld Ageing
Treatment On Tensile Properties And Micro Structural Characteristics Of Friction Welded Aa6061/Sic/Graphite Hybrid Composites, International Journal of Mechanical and Production, 10(2), 2020, p.1275-1284.

44.Sadasivan N, Balasubramanian M. Equal channel angular pressing of gas tungsten arc welded AA6061 alloy. Welding in the World. 2020 Jun 1;64(6):105364.

45.Balasubramanian M, Jayabalan V, Balasubramanian V. Modeling corrosion behavior of gas tungsten arc welded titanium alloy. Transactions of Nonferrous Metals Society of China (English Edition). 2007;17(4):676-80.

46.Balasubramanian M, Jayabalan V, Balasubramanian V. Optimizing the pulsed current gas tungsten arc welding parameters. Journal of Materials Science and Technology. 2006;22(6):8215 .

47.Balasubramanian M, Jayabalan V, Balasubramanian V. Response surface approach to optimize the pulsed current gas tungsten arc welding parameters of Ti-6Al-4V titanium alloy. Metals and Materials International. 2007;13(4):335-44. 